This item was submitted to Loughborough's Research Repository by the author.

Items in Figshare are protected by copyright, with all rights reserved, unless otherwise indicated.

\title{
Estimating economies of scale and scope with flexible technology
}

PLEASE CITE THE PUBLISHED VERSION

http://dx.doi.org/10.1007/s11123-016-0467-1

PUBLISHER

(C) Springer Science+Business Media

\section{VERSION}

AM (Accepted Manuscript)

\section{PUBLISHER STATEMENT}

This work is made available according to the conditions of the Creative Commons Attribution-NonCommercialNoDerivatives 4.0 International (CC BY-NC-ND 4.0) licence. Full details of this licence are available at: https://creativecommons.org/licenses/by-nc-nd/4.0/

\section{LICENCE}

CC BY-NC-ND 4.0

\section{REPOSITORY RECORD}

Triebs, Thomas, David Saal, Pablo Arocena, and Subal C. Kumbhakar. 2019. "Estimating Economies of Scale and Scope with Flexible Technology". figshare. https://hdl.handle.net/2134/21949. 


\title{
Estimating Economies of Scale and Scope with Flexible Technology ${ }^{1}$
}

\author{
Thomas P. Triebs ${ }^{2}$ \\ Ifo Institute - Leibniz Institute for Economic Research at the University of Munich, Germany \\ David S. Saal \\ Loughborough University, UK \\ Pablo Arocena \\ Universidad Pública de Navarra, Spain \\ Subal C. Kumbhakar \\ State University of New York at Binghamton, USA
}

\begin{abstract}
Economies of scope are typically modelled and estimated using a cost function that is common to all firms in an industry irrespective of their type, e.g. whether they specialize in a single output or produce multiple outputs. Instead, we estimate a flexible technology model that allows for type-specific technologies and show how it can be estimated using linear parametric forms including the translog. A common technology remains a special case of our model and is testable econometrically. Our sample, of publicly owned US electric utilities, does not support a common technology for integrated and specialized firms. Our empirical results therefore suggest that assuming a common technology might bias estimates of economies of scale and scope. Thus, how we model the production technology clearly influences the policy conclusions we draw from its characteristics.
\end{abstract}

Keywords: Economies of scale and scope; flexible technology; electric utilities; vertical integration; translog cost function

JEL Classification: D24, L25, L94, C51

\footnotetext{
${ }^{1}$ We would like to thank the participants of the 39th EARIE conference in Rome for their helpful comments. The usual disclaimer applies. Pablo Arocena and David Saal acknowledge financial support from the Spanish Ministry of Economy and Competitiveness (project ECO2010-21242-C03-03).

${ }^{2}$ Corresponding author: Ifo Institute, Leibniz Institute for Economic Research at the University of Munich, Poschingerstrasse 5, 81679 Munich, Germany. triebs@ifo.de.
} 


\section{Introduction}

Economies of scale and scope are fundamental concepts explaining many economic decisions. From a business perspective, they play a central role in assessing the potential benefits of firms' growth and diversification strategies. From an industry perspective, they are central for the determination of efficient market structures. In particular, they influence the restructuring and deregulation of network industries worldwide. For instance, changes in the economies of scale of electricity generation swayed many countries to liberalize electricity markets. Subsequently, the belief that gains from competition would outstrip any losses in economies of scope led many countries to mandate electric utilities to divest their generation assets to prevent discrimination in newly developed wholesale markets. Similarly many banks today argue that economies of scale and scope make large integrated banks more efficient and caution against their break-up to minimize the systematic risk from individual bank failures.

Almost the entire literature on the estimation of economies of scope follows the seminal work of Baumol et al. (1982) and employs a cost function based approach, which allows identification of "the production technology of the firms in an industry". That is, it is assumed that both diversified and specialized firms can be represented by a common technology. However, this approach ignores the theoretical, but empirically testable possibility, that firms engaged in different activities employ different production technologies, which is recognized in the literature (Saal and Parker, 2006; Weninger, 2003; Bottaso et al., 2011). But the full implications for estimating economies of scale and in particular scope have not been widely recognized. The assumption of a common technology when heterogeneous technologies are present will potentially lead to biased estimates of costs and therefore, biased estimates of economies of scale and scope.

Our contribution is to estimate economies of scale and scope with a model where technology can be fully flexible across firm types, e.g. specialized and non-specialized firms. As our approach allows firm type specific technologies to be estimated jointly without separating the sample, we can also test statistically whether the previous literature's assumption of a common technology is appropriate. Similarly, by comparing results with and without imposing the common technology assumption, we can explore its impact on scale and scope economy estimates. Therefore, unlike previous studies that focused on modelling unobserved heterogeneity (e.g. Fetz and Filippini, 2010), our focus is on modelling observed technological heterogeneity, and we thereby explicitly explore the implications of potential heterogeneity in technology between integrated and nonintegrated firms. A further 
contribution is that our approach allows scope economies to be estimated with any linear functional form including the popular translog form introduced by Christensen et al. (1973). This is important because, despite the widely accepted advantages of the translog specification, the non-admission of zero values in the translog form has previously been seen as precluding its use for the estimation of economies of scope (Caves et al. 1980).

We empirically demonstrate the usefulness of our modelling approach by estimating economies of scale and vertical integration (i.e. scope economies between vertical stages) for a sample of publicly-owned US electric companies. Our data is suitable for this task as it comprises both specialized (generating-only and distributing-only) and vertically integrated firms. Our results indicate that within our sample, cost relationships differ between integrated and specialized firms. We find that using our approach in comparison to a common technology model leads to different estimates of scale and in particular scope economies.

The rest of the paper is organized as follows. Section 2 provides the necessary theoretical background including the relevant literature. Section 3 sets out our contribution to the modelling of economies of scale and scope. Section 4 introduces our empirical model and tests. Section 5 has our empirical application. Section 6 presents the results and section 7 gives a short conclusion.

\section{Scale and Scope Economies with a Common Technology}

In this section we provide a summary of the standard approach to model and estimate multiple output cost functions. We first recall the definition of scale and scope economies. Let $N=\{1,2, \ldots, N\}$ be the set of products under consideration, with output quantities $y=\left(y_{1}, \ldots, y_{n}\right)$. The function $\mathrm{C}(y, w)$ denotes the minimum cost of producing the entire set of products, at the output quantities and input prices indicated by the vectors $y$ and $w .{ }^{3}$ The degree of scale economies defined over the entire product set $N$, at $y$, is given by

$$
S_{N}(y, w)=\frac{C(y, w)}{\sum_{i=1}^{n} y_{i} C_{i}(y, w)}=\frac{1}{\sum_{i=1}^{n} \partial \ln C / \partial \ln y_{i}}
$$

\footnotetext{
${ }^{3}$ Duality theory allows us to estimate the underlying production technology via a cost function. Duality theory and the implied restrictions on the cost function ensure that the latter does not violate the physics of production. For an introduction see the survey by Fuss and McFadden (1978).
} 
where $C_{i}$ is the first derivative of cost with respect to product $i$. Returns to scale are said to be increasing, decreasing or constant as $S$ is greater than, less than, or equal to unity, respectively.

Let us consider two subsets, $U \in N$, and $D \in N$ such that $U \cup D=N$, and $U \cap D=\varnothing$. Let $y_{U}$ denote the vector whose elements are set equal to those of $y$ for $i \in U$ and $y_{D}$ denote the vector whose elements are set equal to those of $y$ for $i \in D$. Similarly, $C\left(y_{U}, w\right)$ and $C\left(y_{D}, w\right)$ denote the cost of producing only the products in the subset $U$ and $D$, respectively. The degree of economies of scope between $y_{U}$ and $y_{D}$ is defined as

$$
S C_{U, D}(y, w)=\frac{C\left(y_{U}, w\right)+C\left(y_{D}, w\right)-C(y, w)}{C(y, w)}
$$

The degree of economies of scope SC is measured by (2) where the separation of production is said to increase, decrease or leave unchanged the total cost as $S C$ is greater than, less than, or equal to zero, respectively. Equation (2) shows that the estimation of economies of scope (i.e. the costs and benefits of joint production) requires the comparison of costs between specialized and non-specialized firms at a given vector of input prices. In our below application, this measure of economies of scope can be readily interpreted as a measure of firm's vertical integration economies in a multi-stage context. Thus, if $N$ denotes the entire product set along the firm's vertical chain, $U$ denotes the subset of upstream only products, and $D=N-U$ denotes the subset of downstream only products, then (2) measures the degree of vertical integration economies.

For empirical estimation of (1) and (2) the researcher has to choose an appropriate functional form, obtain relevant data, and decide on a model of the underlying production technology. We now discuss each point in turn. For multiproduct cost functions, Caves et al. (1980) set out three criteria for the ex-ante choice of functional forms: satisfaction of regularity conditions, limited number of parameters, and the ability to admit zero values for some outputs. In the general empirical literature the translog and the quadratic are the most popular functional forms. However, the translog form, despite its theoretical appeal and wide application, has an important drawback in that the cost function is undefined for a zero output level. This is important, because the measurement of economies of scope requires the comparison of costs between specialized and integrated firms; and specialization requires that the production of at least one of the outputs is zero. 
One solution to the problem of zero output values is to estimate the costs at an arbitrarily small level of output. Thus, several studies substitute an arbitrary small positive constant (e.g.: 0.01) for zero output values (Jin et al., 2005; Akridge and Hertel, 1986; Gilligan and Smirlock, 1984; Cowing and Holtmann, 1983). We will use this approach as our empirical benchmark model below. Other studies replace zero values with the minimum value of each output within the sample under consideration (Goisis et al., 2009; Rezvanian and Mehdian, 2002) or with a value equal to ten per cent of output at the sample means (Kim, 1987). An alternative solution is to use the Box-Cox transformation on output variables, e.g., the generalized (hybrid) translog function, as suggested by Caves et al. (1980). Both approaches, however, introduce an unknown bias (e.g. Berger et al., 1987; Gunning and Sickles, 2009), while producing erratic estimates due to the degenerate limiting behaviour of the translog cost function (Röller, 1990).

Some studies use a translog form on a subsample of firms with strictly positive outputs only, which allows them to estimate cost complementarity between outputs, i.e. the sign of the second-order derivative $\partial^{2} C / \partial y_{G} \partial y_{U}$ (Fuss and Waverman, 1981; Gilsdorf, 1994). However, cost complementarity is a sufficient but not a necessary condition for the presence of scope economies as shared fixed costs are another potential source of economies of joint production (Baumol et al., 1982).

When specialized firms are absent (instead of being dropped) from the sample, the problem of zero outputs does not arise in estimation. Instead, it appears in predicting the counterfactual, i.e., predicting the costs of specialized firms from the estimated cost function which is assumed to be the same for specialized and non-specialized firms. In most studies the reason for observing integrated firms only is the non-existence of specialized firms in the industry. Although the absence of specialized firms might be taken as prima facie evidence for the existence of economies of scope, it is not obvious that the existing industry structure is only driven by costs considerations, particularly for regulated or publicly owned industries. Conversely, observing specialized firms only does not provide evidence for the non-existence of economies of scope as this could reflect historical precedent, mandated industry restructuring, or other institutional factors that have influenced an industry's development.

The quadratic functional form is frequently employed as it readily admits zero values and is easy to implement (e.g. Mayo, 1984; Kaserman and Mayo, 1991; Jara-Díaz et al., 2004; Fetz and Filipini 2010; Jara and Ramos-Real 2011; Arocena et al., 2012). However, it also has an important drawback: imposing homogeneity in input prices as a regularity condition on the quadratic form sacrifices flexibility (Caves et al. 1980, p. 478). Several 
authors (e.g. Martínez-Budría et al., 2003) argue that normalizing cost and input prices by one of the input prices prior to estimation will circumvent this problem. However, the results are not invariant to the choice of normalized input price. Other applied studies propose alternative functional forms which allow for zero outputs, (but not for zero values in input prices or control variables), the Composite (e.g. Fraquelli et al., 2005), or the Generalized Composite form (e.g. Bottasso et al., 2011). For these forms the coefficients can be difficult to estimate and sometimes they are not even identified. Convergence is another problem because the models are highly non-linear in parameters. We do not see any economic or econometric rationale for using the Box-Cox transformation just because the transformation approaches to a log transformation as the Box-Cox parameter approaches to zero. We believe that using a true zero value instead of the Box-Cox transformation is a better solution. One can argue for a similar transformation for the other variables which are non-zero (Berndt and Khaled, 1979). Moreover, a further disadvantage for applied research and policy advice is that individual coefficients have no direct economic meaning which reduces transparency.

We finally emphasize that the econometric literature almost always uses a common multiproduct cost function, which is consistent with the definitions of scale and scope economies provided in (2) and (3) above. However, this assumes poolability across different firm types and the presence of a single underlying production technology for all firms, regardless of their degree of specialization. ${ }^{4}$ On econometric grounds this maintained assumption is hard to justify without empirical testing, and in many cases there are reasons to believe that such an assumption is inappropriate (e.g. Bottasso et al., 2011). Weninger (2003) argues that the presence of cost (dis)complementarities reflects the differences in the cost structure between diversified and specialized firms (the latter by definition produce no complementary goods). In the same vein, Garcia et al. (2007) note that when considering vertical scope economies in multistage industries, firms' production technologies may differ with their level of vertical organization. That is, they suggest that the data generating process of the cost of a firm does depend on the vertical organization of the firm. The next section therefore proposes a general model with firm type cost function flexibility.

Thus, we do not pursue an approach that continues an endless game of requiring the estimation of more and more generalized forms. Instead, we employ what we believe to be a theoretically, both economically and econometrically, correct approach, which is to estimate

\footnotetext{
${ }^{4}$ A related literature that uses nonparametric estimators (Charnes et al., 1978) to measure economies of scope always uses models that allow for different technologies across firm types and emphasizes that it is these differences that underlie economies of scope (Färe 1986).
} 
separate functions for specialized and integrated firms, (e.g. Weninger, 2003; Garcia et al., 2007), while also allowing for a statistically valid test of this separation. Stated differently, if some outputs are genuinely zero and the technologies are genuinely different, separate estimation is theoretically appropriate. But since the specification of separate technologies will not necessarily be appropriate in all empirical applications it is also theoretically and empirically necessary to allows testing of the separate technology assumption. In sum, our approach is a generalization of the separate regression approach, which also allows the restriction and testing of a common technology assumption.

\section{Estimating Economies of Scale and Scope with Firm Type Cost Function}

\section{Flexibility}

This section builds on Fuss and Waverman (2002) and proposes a flexible technology across firm types for the estimation of scale and scope economies. Let $T=\{I, U, D\}$ be the set of firm types, where $I, U, D$ refer to integrated, upstream, and downstream firms. Integrated firms $I$ produce the entire output vector $y=\left(y_{1}, \ldots, y_{n}\right)$ as defined above, while upstream $U$ and downstream $D$ firms produce output vectors $y_{U}$ and $y_{D}$, respectively. That is, we allow different firm types to have different underlying production possibilities. We therefore define a firm type flexible cost function as

$$
C=\left\{\begin{array}{l}
C^{I}(y, w) \\
C^{U}\left(y_{U}, w\right) \\
C^{D}\left(y_{D}, w\right)
\end{array}\right.
$$

where $w$ is the vector of input prices. ${ }^{5}$ Equation (3) allows the cost function to be flexible across firm types. In (3) we respectively define the upstream cost function as $C^{U}$ $\left(y_{U}, w\right)$ and the downstream cost function as $C^{D}\left(y_{D}, w\right)$ instead of $C\left(y_{U}, w\right)$ and $C\left(y_{D}, w\right)$. This allows for potentially distinct technologies associated with the production of the distinct subsets of outputs for the upstream $\left(y_{U}\right)$ and downstream $\left(y_{D}\right)$ firms rather than simply restricting $C^{I}(y)$ by assigning zero values for non-produced outputs, as is common in most previous studies of scope economies. We emphasize that our approach follows the seminal work of Panzar and Willig (1981, p. 268-269), which clearly partitions the integrated output set into distinct nonintersecting sub-sets produced by specialized firms when defining scope

\footnotetext{
${ }^{5}$ For notational convenience and ease of exposition, we do not index input prices by utility type.
} 
economies. Panzar and Willig's theoretical approach defined specialized output sets as a subset of all outputs and not as the simple restriction of unproduced outputs to zero output quantities. However, it is less clear from their notation whether they allowed technologies to differ by firm type. Fuss and Waverman (2002) stated that the difference between technologies is "sufficiently fundamental that these technologies [for specialized firms] cannot be recovered [...] simply by setting the missing output equal to zero”. Fundamentally, if $C^{D}\left(y_{D}, w\right) \neq C^{I}\left(0, y_{\mathrm{D}}, w\right)$ and/or $C^{U}\left(y_{U}, w\right) \neq C^{I}\left(y_{U}, 0, w\right)$ this implies that the underlying technology employed by integrated firms, even when only producing a specialized subset of its potential outputs is distinct from the production technology(ies) associated with specialized firms.

The most straightforward way to estimate (3) is to estimate separate models for each firm type (e.g. Weninger, 2003; Garcia et al., 2007). In essence, this is also the approach followed by the related literature that uses mathematical programming techniques to estimate economies of scope, following the pioneering work by Färe (1986). We propose joint estimation of the three technologies specified in (3) first without imposing constraints and then imposing constraints to test for common technology. To illustrate the idea we write the three technologies as

$$
\begin{aligned}
& C^{I}(y, w)=X^{I} \Gamma^{I}+u^{I} \\
& C^{U}\left(y_{U}, w\right)=X^{U} \Gamma^{U}+u^{U} \\
& C^{D}\left(y_{D}, w\right)=X^{D} \Gamma^{D}+u^{D}
\end{aligned}
$$

where $X$ variables are covariates (outputs and input prices), $\Gamma$ represents the firm type specific unknown technology parameters, and $u$ are noise terms. With an appropriately designed matrix $X$, the formulation in (3a) fits a quadratic (when the variables are in levels) and a translog specification when the variables are logged. Thus, regardless of the cost specification, we can stack the equations in (3a) and write it as

$$
\begin{gathered}
C(y, w)=X \Gamma+u \\
\text { where } X=\left[\begin{array}{ccc}
X^{I} & 0 & 0 \\
0 & X^{U} & 0 \\
0 & 0 & X^{D}
\end{array}\right] \text { and } \Gamma=\left[\begin{array}{c}
\Gamma^{I} \\
\Gamma^{U} \\
\Gamma^{D}
\end{array}\right] \text {. }
\end{gathered}
$$


Moreover, the stacked equation (3b) can be estimated using OLS/GLS. However, note the data structure in $X$ : the matrices below $X^{I}$ are filled with zeros because these data are not relevant to integrated firms, while a similar structure is used for upstream and downstream firms.

The technologies in (3a) can alternatively be written with the use of dummy variables

$$
C(\cdot)=I * C^{I}\left(y, w, \Gamma^{I}\right)+U * C^{U}\left(y_{U}, w, \Gamma^{U}\right)+D * C^{D}\left(y_{D}, w, \Gamma^{D}\right)
$$

where the three dummy variables $I, D$ and $U$ take the value one if the firm is integrated or specializes in the downstream or upstream activity, respectively. The first term in equation (4) represents integrated firms and is "activated" or "turned on" only if $I$ takes the value of one. Similarly, the second and third terms represent upstream and downstream only firms, respectively. The second (third) term is activated when $U(D)$ takes a value of unity. We refer to this model as a firm type flexible technology model as opposed to a restricted or common technology model.

Note this is not a single cost function theoretically, but instead combines the three separate technologies allowed for in (3). However, we write it this way to illustrate that for estimation purposes it is viewed as a single cost function. This model allows both the variables and associated parameters to vary between the three firm types. The firm type cost functions in $C(\cdot)$ can take any functional form including a translog form. Note that $C^{I}(\cdot)$ is defined for the full set of outputs, whereas $C^{U}(\cdot)$ and $C^{D}(\cdot)$ are defined for subsets of outputs $y_{U}$ and $y_{D}$ respectively.

We note that Battese (1997) and Battese et al. (1996) employ a related artifice in the estimation of production functions when some observations have zero input values. Particularly, Battese et al. (1996) investigate the production function for wheat production, where some farmers use fertilizers or pesticides while others do not. Thus, Battese (1997) suggests the introduction of a dummy variable associated with the incidence of the observations that take zero values, which permits the intercepts to be different for farms with positive and zero inputs, while maintaining the same parameters for inputs employed by all firms. Our model generalizes Battese's restricted method, and allows a fully flexible technology specification, where technologies, and hence all parameters, can differ fully between firm types.

When using the translog form for each of the technologies with parameters of their own, we can write (4) in log form as 


$$
\ln C(\cdot)=I * \ln C^{I}\left(y, w, \Gamma^{I}\right)+U * \ln C^{U}\left(y_{U}, w, \Gamma^{U}\right)+D * \ln C^{D}\left(y_{D}, w, \Gamma^{D}\right)
$$

where $\ln C^{I}\left(y, w, \Gamma^{I}\right), \ln C^{U}\left(y_{U}, w, \Gamma^{U}\right)$ and $\ln C^{D}\left(y_{D}, w, \Gamma^{D}\right)$ are three different translog functions for integrated, upstream and downstream firms. If we write it in stacked form (similar to (3b)) as $\ln C(y, w)=\ln X \Gamma+u$ we need to pay attention to the data matrix $\ln X$. In this case, it requires the following adjustment for empirical implementation. Assume for illustration that the number of integrated, downstream and upstream firms are $n_{1}, n_{2}$ and $n_{3}$, so that the total number of firms is $n=n_{1}+n_{2}+n_{3}$. Thus $\ln C(\cdot)$ in (4a) is defined for all $n$ firms. However, $\ln C^{I}\left(y, w, \Gamma^{I}\right), \ln C^{U}\left(y_{U}, w, \Gamma^{U}\right)$ and $\ln C^{D}\left(y_{D}, w, \Gamma^{D}\right)$ are respectively defined for only $n_{1}, n_{2}$ and $n_{3}$ firms. This problem can be readily solved by appropriately filling the blanks (we say blanks when something is not in the data, instead of zero). For example, there will be $n_{2}+n_{3}$ blanks for the (log) output variables for the integrated firms. These blanks can be replaced by arbitrary, positive numbers because when we multiply them by the $I$ dummy these $n_{2}+n_{3}$ observation that do not belong to the integrated firms will be completely eliminated. We can do the same for the upstream and downstream firms. The blanks (for outputs and input prices) for each firm type are filled and then removed by the appropriate firm type dummy. We emphasize that this approach preserves firm type flexibility by not imposing the assumption that $C^{D}\left(y_{D}, w\right)=C^{I}\left(0, y_{D}, w\right)$ and/or $C^{U}\left(y_{U}, w\right)=C^{I}\left(y_{U}, 0, w\right)$. However, in contrast to the separate estimation approach, the appropriateness of this assumption can be readily tested for by imposing parameter equalities across the three firm type technologies.

We note that Bottasso et al. (2011) allow costs to depend on the firm type using a Generalized Composite function. They found that it is an undue restriction to impose a common technology for two types of water companies in England and Wales, water-andsewage and water-only companies. However, they used a Box-Cox transformation which defeats the purpose of using firm type specific technologies. The Box-Cox transformation in their formulation is used to handle observations with zero values so that a common technology can be estimated. Unlike the model used by Bottasso et al. (2011) our model is much simpler and does not require a Box-Cox transformation.

Given the firm type flexible cost function in (3) we can rewrite the textbook definition of economies of scale and scope. For scale we rewrite (1) as

$$
S_{N}^{T}(y, w)=\frac{C^{T}\left(y_{T}, w\right)}{y_{T} C_{i}^{T}\left(y_{T}, w\right)} \quad \text { for specialized firms }(T=U \text { or } D) \text { and }
$$




$$
S_{N}^{T}(y, w)=\frac{C^{T}\left(y_{T}, w\right)}{\sum_{i=1}^{2} y_{i} C_{i}^{T}\left(y_{T}, w\right)} \text { for non-specialized firms }(T=I)
$$

Thus, returns to scale now depend on the firm type $T$. Similarly, for the degree of economies of scope we rewrite (2) as

$$
S C_{U, D}(y, w)=\frac{C^{U}\left(y_{U}, w\right)+C^{D}\left(y_{D}, w\right)-C^{I}(y, w)}{C^{I}(y, w)}
$$

where we now allow for different technologies for the three firm types. Unlike in Baumol et al. (1982), both differences in cost levels and differences in technology drive economies of integration. This model is general in the sense that it allows specialized firms to operate with a different underlying production technology than integrated firms. It also allows for the imposition and testing of the common technology assumption through imposition of appropriate parameter restrictions. It should be obvious from these equations that it is really the estimates of the underlying technologies that drive economies of scale and scope. If the estimates of the technologies are incorrect the estimates for economies of scale and scope will be incorrect as well.

\section{Modelling and estimation approach}

Applying a translog form to (4a) we estimate the following two output model ${ }^{6}$

\footnotetext{
${ }^{6}$ Although we are using notations $y_{U}$ and $y_{D}$ these can be generically labeled as $y_{1}$ and $y_{2}$ so that $y_{U}$ and $y_{D}$ for the integrated firm are nothing but $y_{1}$ and $y_{2}$.
} 
(7) $\ln C=I *\left[\alpha_{0}^{I}+\beta_{1}^{I} \ln y_{U}+\beta_{2}^{I} \ln y_{D}+\sum_{k=1}^{M} \gamma_{k}^{I} \ln w_{k}+\frac{1}{2} \rho_{1}^{I}\left(\ln y_{U}\right)^{2}+\frac{1}{2} \rho_{2}^{I}\left(\ln y_{D}\right)^{2}+\right.$

$$
\begin{aligned}
& +\rho_{12}^{I}\left(\ln y_{U}\right)\left(\ln y_{D}\right)+\frac{1}{2} \sum_{k=1}^{M} \sum_{j=1}^{M} \lambda_{k j}^{I} \ln w_{k} \ln w_{j}+\sum_{k=1}^{M} \theta_{1 k}^{I} \ln y_{U} \ln w_{k} \\
& \left.+\sum_{k=1}^{M} \theta_{2 k}^{I} \ln y_{D} \ln w_{k}\right]+ \\
& +U *\left[\alpha_{0}^{U}+\beta^{U} \ln y_{U}+\sum_{k=1}^{G} \gamma_{k}^{U} \ln w_{k}+\frac{1}{2} \rho^{U}\left(\ln y_{U}\right)^{2}\right. \\
& \left.+\frac{1}{2} \sum_{k=1}^{G} \sum_{j=1}^{G} \lambda_{k j}^{U} \ln w_{k} \ln w_{j}+\sum_{k=1}^{G} \theta_{k}^{U} \ln y_{U} \ln w_{k}\right]+ \\
& +D *\left[\alpha_{0}^{D}+\beta^{D} \ln y_{D}+\sum_{k=1}^{L} \gamma_{k}^{D} \ln w_{k}+\frac{1}{2} \rho^{D}\left(\ln y_{D}\right)^{2}\right. \\
& \left.+\frac{1}{2} \sum_{k=1}^{L} \sum_{j=1}^{L} \lambda_{k j}^{D} \ln w_{k} \ln w_{j}+\sum_{k=1}^{L} \theta_{k}^{D} \ln y_{D} \ln w_{k}\right]+u
\end{aligned}
$$

where $C=$ total costs, $y_{U}=$ the quantity of upstream output, $y_{D}=$ the quantity of downstream output, $w_{k}=$ the price of input $k, M=$ the number of inputs used by integrated firms, $G=$ the number of inputs used by upstream firms, $L=$ the number of inputs used by downstream firms, and the Greek letters stand for the unknown population parameters.

The cost function is required to satisfy the following symmetry and linear homogeneity (in input prices) constraints. Ignoring firm type indicators for ease of illustration, these are:

$$
\rho_{12}=\rho_{21} ; \lambda_{k j}=\lambda_{j k} \text {, for } \mathrm{U}, \mathrm{D} \text {, and I }
$$

The linear homogeneity constraints are automatically imposed if we divide cost and input prices by one arbitrarily chosen input price and drop the corresponding share equation. 
Using Shephard's Lemma and the symmetry constraint we obtain share equation (10) for input $k$.

$$
\begin{aligned}
s_{k}= & I *\left[\gamma_{k}^{I}+\theta_{1 k}^{I} \ln y_{U}+\theta_{2 k}^{I} \ln y_{D}+\sum \lambda_{k j}^{I} \ln w_{j}\right] \\
& +U *\left[\gamma_{k}^{U}+\theta_{k}^{U} \ln y_{U}+\sum \lambda_{k j}^{U} \ln w_{j}\right] \\
& +D *\left[\gamma_{k}^{D}+\theta_{k}^{D} \ln y_{D}+\sum \lambda_{k j}^{D} \ln w_{j}\right]
\end{aligned}
$$

We estimate this system of the cost function and share equations using the iterated seemingly unrelated regression (SUR) technique (Zellner, 1962) after adding classical error terms in the cost function and the cost share equations. The additional structure imposed by the share equations makes the estimates more efficient as we add equations but do not increase the number of parameters. All variables are demeaned so that the translog expansion is around the sample mean across all firms and the first order coefficients can be interpreted as elasticities at the sample mean.

In any case, it should be clear to the reader that the flexible technology model formulated above is applicable to any functional form. Nevertheless, we emphasize that we have specifically chosen the translog specification in our empirical model precisely because we wish to show that our approach is particularly useful for the translog form, which is normally considered to be problematic for the empirical analysis of scope economies.

If the parameters for each firm type technology are different, one can estimate them separately by using the respective cost function and the share equations. However, a separate regression approach always assumes the existence of different technologies without allowing the possibility of hypothesis testing with regard to whether this assumption is valid. Therefore, there are several advantages of our joint estimation approach over estimating separate equations using data for each group. Only joint estimation is truly flexible in the sense of allowing for both the possibility of a common technology or differences in firm type technologies. Thus, even if there are enough observations in each group to separately estimate each firm type technology, separate estimation may inappropriately impose different technologies. More precise estimates are obtained by estimating all the parameters jointly and by using a system approach. The other significant advantage is to test hypotheses across firm type technologies which cannot be done if these technologies are estimated separately. In the joint estimation the implicit (default) assumption is that the error variances and covariances (in the cost and share equations) are the same for different firm type technologies. This can be 
easily generalized. In the separate estimation by firm type the variances and covariances vary across firm type, and it is not possible to impose restrictions across firm type technologies because they are estimated separately.

As usual we make the assumption that the errors are i.i.d.. We also assume that inefficiency (which we do not model explicitly) is i.i.d. and thereby inefficiency would only affect the intercept. If the mean of inefficiency is different for different types of firms (Integrated, Upstream, and Downstream firms), it will change the intercept for each type. Inefficiency does not affect the elasticity estimates. Thus, the presence of differences in mean inefficiency across types is a further argument in favor of our flexible technology approach. ${ }^{7}$

Here, we consider two outputs, which results in three types of technologies. Generally, our flexible technology model allows testing for as many technologies as can reasonably be defined. In practice, the number of technologies that can be accommodated would be constraint by the data available.

We perform the standard likelihood ratio test for inferences across groups. First, we test whether restriction of the three firm type technologies to a single common technology is valid. This common technology restriction is readily tested with a Likelihood ratio test by imposing the following restrictions

$$
\begin{aligned}
H_{0}: \alpha^{I} & \equiv \alpha^{U} \equiv \alpha^{D} \\
\beta^{I} & \equiv \beta^{U} \equiv \beta^{D} \\
\gamma^{I} & \equiv \gamma^{U} \equiv \gamma^{D} \\
\rho^{I} & \equiv \rho^{U} \equiv \rho^{D} \\
\lambda^{I} & \equiv \lambda^{U} \equiv \lambda^{D} \\
\theta^{I} & \equiv \theta^{U} \equiv \theta^{D}
\end{aligned}
$$

These restrictions can be easily implemented by appropriately defining the data matrix $\ln X$ in the formulation $\ln C(y, w)=\ln X \Gamma+u$.

Second, we can also separately test the restriction of the upstream (downstream) cost function parameters to be equal to the integrated parameters. Thus, for example, to test equivalence between the integrated firm parameters and the upstream firm parameters, we would test a null hypothesis after dropping the second equality signs and setting all the downstream only parameters to zero in (11).

\footnotetext{
${ }^{7}$ We thank an anonymous referee for making this point.
} 


\section{Empirical application}

To further illustrate the usefulness of the flexible approach to deal with technological heterogeneity, we apply it to investigate the presence of economies of vertical integration in the electric power industry. In this industry the estimation of the potential cost reduction from integrating the different stages of electricity supply has been the subject of several studies. That is, the issue consists of determining whether the cost of a vertically integrated utility that produces and distributes certain amount of power, is lower (higher) than the cost of producing and distributing the same amount of power by means of two separate firms: a stand-alone generator and a stand-alone distributor. This issue has important policy implications regarding the assessment of the costs and benefits of the unbundling or vertical separation implemented in the electricity industry as part of the major restructuring reforms carried out over the past two decades in many countries. Meyer (2012) provides a broad survey of this literature.

The data is for US local government owned electric utilities and were sourced from the EIA-412 survey, which was gathered by the U.S. Energy Information Administration until 2003. The data comprises three firm types: upstream, integrated, and downstream. Our sample only includes conventional fossil-fuel generators to avoid the bias from combining very different power generation technologies as well as the complexity of allowing for both vertical and horizontal integration economies when interpreting the scope economies estimates (Arocena et al., 2012). Downstream firms (D) are pure power distributors, and integrated firms $(I)$ engage in both activities, i.e. they generate electricity from fossil fuels only and distribute the power. The data is an unbalanced panel for the years 2000 to 2003. Table 1 illustrates the distribution of firms across the output space (using electricity generation as the upstream output and peak demand as the downstream output). The table gives the observation count by size bracket for the upstream and downstream activities. The first row and first column give the counts of fully specialized firms and the diagonal gives the count for fully integrated firms. There are 84 generation only and 148 distribution only firmyear observations. Clearly the space between the diagonal and the two axes is less densely populated. The total number of observations is 436 .

[Place Table 1 about here] 
We define the following variables. Our dependent variable, total cost $(C)$ is measured in US dollars and is the sum of capital, fuel and operating expenses. Operating expenses is the sum of generation O\&M, distribution O\&M, Customer Accounts Expenses, Customer Service \& Informational Expenses, Sales/Marketing Expenses and a pro-rata Admin \& General O\&M. We do not include any transmission expenses. Likewise, purchased power expenses are excluded to avoid double counting generation costs, as is thoroughly discussed in the related literature (e.g. Gilsdorf, 1994; Kwoka, 2002; Jara-Díaz et al., 2004; Fraquelli et al., 2005). Capital expense is the capital stock multiplied by the interest rate paid on long-term debt, plus depreciation expenses. The capital stock $(K)$ is the written down accounting value of fixed assets.

We consider a single upstream output, measured by net electricity generated $\left(\mathrm{y}_{\mathrm{G}}\right)$, and a single distribution output $\left(\mathrm{y}_{\mathrm{D}}\right)$. Given its complexity, it is common to model electricity distribution as a multiple output technology including total distribution volumes, peak demand, customers served, and/or distribution network length. However, while all these output attributes are important, their inclusion also tends to cause serious multicollinearity problems in estimation (Arocena et al., 2012; Kuosmanen, 2012). Given that the purpose of this paper is primarily methodological, we chose a more parsimonious model for two reasons. Firstly, to avoid multicollinearity among second order terms due to strong correlation between distribution output measures. Secondly, a simple model specification saves the estimation of the large number of parameters typically required by the translog functional form when the number of outputs increases. Therefore, we focus on results based on a single distribution output module while experimenting with an alternative distribution output: power delivered.

We believe that the model that uses the peak demand specification has two important advantages. Firstly, it is consistent with the logic that electrical system design and its associated costs are to a larger extent driven by peak rather than average loads. Secondly, in our application peak demand is less correlated with the generation output than power delivered. In any case, the qualitative results are robust to both output specifications.

Finally, we include input prices for capital $\left(w_{K}\right)$, fuel $\left(w_{F}\right)$ and others $\left(w_{O}\right)$. The capital price $\left(w_{K}\right)$ is capital expense divided by the capital stock $(K)$. The fuel price $\left(w_{F}\right)$ is the fuel expenditure divided by BTUs of fuel consumption. The final input variable that we define is an Other Operating Costs (OC) variable. This variable includes both labour costs and other operating costs excluding fuel expenses (e.g., outsourced services). Since detailed labour cost data were not available in the EIA-412 survey, we had to specify a single aggregate measure to capture these items. The price of other $\left(w_{O}\right)$ is therefore defined as the state-level Census 
Bureau index of average wages for all employees. The quantity measure for other inputs is then obtained implicitly by deflating the cost measure by this price index. The price of other inputs is the numeraire used to impose homogeneity in input prices.

We note that our model assumes that firms treat input prices and output quantities as exogenous elements in their decision processes, thereby following the argument of Nerlove (1963) and Christensen and Greene (1976). These two seminal studies of electricity industry costs emphasize that, unlike for production function estimation where input quantities are likely to be endogenous, cost function estimation is appropriate, given the reasonable assumption that factor prices are determined in competitive markets or through regulation, while electricity output is determined by consumer demand. Our sample consists of regulated electric utilities that are obliged to serve all customers. Further, electric power cannot be economically stored and thereby must be supplied on demand. Hence the decision on outputs is exogenous to the firm. Thus, our empirical estimation approach builds on a well-established literature that relies on dual cost function estimation to specifically avoid the endogeneity problems that can affect production function estimation.

Table 2 provides summary statistics by firm type. The table shows that there are important differences across the three firm types and that there are large variances within each group. Dots indicate that a variable is not applicable to the type of firm. Regarding the outputs, on average, generation only companies generate more than twice the amount of electricity as integrated firms, arguably reflecting the fact that integrated firms can choose between making and buying electricity. By contrast, the mean of the distribution output is virtually the same for integrated firms and pure distributors. We note that the publicly owned utilities in our sample are much smaller in terms of output than the investor owned utilities employed in previous studies on US electric utilities (e.g., Kaserman and Mayo, 1991; Kwoka, 2002; Arocena et al., 2012, amongst others).

Mean prices of capital and other inputs are very similar across firm types. However, the estimated price of fuel for integrated firms is substantially higher than the price for generation only firms. We believe that this reflects the fact that our sample only includes fossil-fuel generators (i.e. no nuclear, hydro, or renewables). Fossil-fuel based generation involves the combustion of a mix of different fuels, mostly different coal types (e.g. lignite/brown coal, bituminous coal/steam coal, anthracite/hard coal), natural gas and oil fuels (e.g. fuel oil, diesel oil). These fuels show substantial price differences. Therefore, we believe that the average price per BTU of fuel differs across utilities according to the mix of fossil fuels used in their available power plants. In our sample, vertically integrated firms use a 
higher proportion of natural gas and oil fuels, which are typically more expensive than coal. Further, lower volumes of power produced, as is the case for the average vertically integrated firms in our sample, usually means a lower number of stable operating hours, facing more interrupted production and more frequent start-ups, and thereby a greater use of ancillary and backup fuels (e.g. diesel oil).

Finally, we again caution the readers that our empirical application is meant to primarily serve as a methodological demonstration rather than an in-depth study of the publicly owned US electricity sector's performance. Thus, while it is possible that more accurate estimates of scope and scale economies in the power industry could and should be obtained, this would require a more comprehensive and detailed data base than the one we have. In particular, it would require additional variables in order to better control for differences in the operating environment faced by electric utilities.

\section{[Place Table 2 about here]}

\section{Results}

This section presents the parameter estimates and estimates for economies of scale and scope. We normalize the data at the sample mean so that the first order coefficients of the translog functions can be interpreted as elasticities (of the respective variables) at the mean of the data. Table 3 gives the coefficient estimates for our three models, in which peak demand measures the distribution output ${ }^{8}$. Under Model 1 we report the estimates of the firm type flexible technology model as detailed in equation (7) above. Note that even though the estimates for the three firm types are given in different columns all the parameters are estimated using a single regression. The first three rows in each column give the firm type specific constant. Model 2 reports the parameter estimates from the conventional commontechnology model for the translog specification, where zeros were replaced by an arbitrary small number (0.0001). Finally, Model 3 reports the parameters estimated allowing for firm type technologies by using separate regressions for each firm type.

Statistics for the goodness of fit at the bottom of the Table 3 show that the R-squared statistics (for the cost function equations) are very high for all models, but highest for Model

\footnotetext{
${ }^{8}$ In the interest of brevity, we do not report the coefficient estimates for the models that define the distribution output as power delivered. They are available upon request. In any case, Table 4 below shows the scale and scopes estimates for both distribution output specifications.
} 
1. We observe that the coefficients, and hence estimated cost elasticities of Model 1 are very close to those obtained from Model 3. In contrast, the individual coefficients for the conventional common-technology specification with replacement of zero outputs with an arbitrary number reported in Model 2 differ greatly.

We also check for violations on the assumption that the technology is concave in input prices for Model 1 and 2. There are no violations for the price of fuel. However, there are violations for the price of capital. In Model 1, 63 per cent of the upstream observations violate the concavity constraint. For integrated and downstream observations the percentages are 15 and 6, respectively. Despite allowing for different parameter estimates the variable definitions are identical across types of firms. This might be too strong an assumption. For Model 2, 18 per cent of the observations violate the concavity constraint for the price of capital. There are no violations of the monotonicity assumption.

\section{[Place Table 3 about here]}

We next perform statistical tests using Model 1 for the null hypothesis that the different firm types share a common technology. We reject the null hypothesis in (11) that the technologies are the same across the different firm types at the 1 per cent level. Table 4 provides values of the relevant statistics. The first column tests equality of all coefficients across the three firm types. The second and third columns show the test results for the hypothesis that the technology of a specialized firm is the same as the technology for the integrated firm. The second column for instance tests whether the parameters relating to the upstream activity only are identical for upstream only and integrated firms. We stress that inference on common technology is an important benefit of the firm type flexible technology approach specified in (3), (4) and (7). Thus, while Model 3 demonstrates that it is possible to estimate different technologies for the different production structures with separate regressions, only our flexible technology approach in Model 1 allows this direct statistical test of whether the underlying technological parameters for the three firm types are statistically different, and therefore an appropriate cost function specification.

\section{[Place Table 4 about here]}

Table 5 reports estimates of the economies of scale (S) and scope (SC) for the three models and the two distribution output definitions. All estimates are at the sample mean. 
Consider the estimates for economies of scale. For each model we report estimates of economies of scale for integrated firms as well as estimates for the two types of specialized firms. The degree of scale economies defined over the entire integrated product set does not widely differ either across models or distribution output specification: all models provide evidence for increasing returns to scale at the sample mean. Further, the scale economy estimates for pure generators and distributors also consistently indicate increasing returns to scale under both Models 1 and 3.

A further drawback of the conventional common-technology approach is that it is not feasible to estimate the degree of scale economies for single output companies. Thus, the standard approach here is to compute product-specific returns to scale, defined as the ratio of the average incremental cost of a product to its marginal cost (Baumol et al., 1982), e.g.

$$
S_{i}(y)=\frac{I C_{i}(y)}{y_{i} C_{i}(y)}=\frac{C(y)-C\left(y_{N-i}\right)}{y_{i} C_{i}(y)}=\frac{A I C_{i}}{C_{i}(y)} \text { for } i=U, D
$$

where $I C_{i}$ is the incremental cost of the product $i, C(y)$ is the cost function, $C_{i}(y)=\partial C(y) / \partial y_{i}$ is the marginal cost of product $i$, and $y_{N-i}$ is a vector with a zero component in place of $y_{i}$ and components equal to those of $y$ for the remaining products. That is, $S_{U}(y)$ $\left(S_{D}(y)\right)$ relates to the increment in the firm's cost which results from the addition of certain level of upstream (downstream) product to the firm's set of outputs, holding the magnitude of all other products constant. Therefore the estimates for the common technology approach are not readily comparable with the scale measures obtained from the other two models. Nevertheless, the estimates for scale for the specialized firm differ between Model 2 and Model 1 (Model 3). In particular, the estimate for the upstream technology in Model 2 is unrealistically low.

\section{[Place Table 5 about here]}

We now turn to the estimates for economies of scope (SC), also shown in Table 5. Models 1 and 3 report almost identical positive estimates at the sample mean. Thus, the separate production of output vectors $y_{G}$ and $y_{D}$ increases the total cost by $4.3 \%$ to $4.4 \%$ when distribution output is measured by peak demand, and by $0.6 \%$ to $0.9 \%$ when it is measured by the amount of power delivered. In contrast, the estimated economies of scope are much stronger using a conventional common technology approach with zero replacement. The 
estimate from Model 2 suggests that the vertical separation of the average sample firm would increase total costs by $35.2 \%$ to $40.1 \%$, depending on the distribution output definition. In quantitative terms such an estimate seems somewhat unrealistic but is within the range of results reported in some previous studies for the US electric industry (e.g. Kaserman and Mayo, 1991; Kwoka, 2002; Greer, 2008) who also use common-technology quadratic models.

Finally, as shown by Fraquelli et al. (2005), with a translog specification scope economies are very sensitive to the chosen value of the arbitrary small number. In our application, scope economies estimates for Model 2 range from 26.2\% when zeros are replaced by 0.001 , to $54.1 \%$ when are instead replaced by 0.00001 . This evidence highlights the advantage of the proposed approach employed in Model 1 compared to previous conventional translog-based empirical studies: without the proposed firm type flexible method it is simply not possible to provide reliable estimates for scope and scale economies by means of a translog cost frontier specification.

\section{Conclusion}

This paper has highlighted the importance of modelling separate technologies for different observed firm types when estimating economies of scale and scope. And it demonstrated the feasibility of estimating scope economies using a translog form. This is accomplished by relaxing the generally accepted practice of estimating a single cost function model, while assuming that both integrated and specialized firms operate with the same production technology. The relaxation of this assumption immediately eliminates the wellknown zero output problem for translog estimation of multiple output technologies, but also requires the availability of data for both specialized and integrated firms. However, the same data restriction also applies, for example, to quadratic cost function models that impose a common technology, as it is generally accepted, that even with a common technology assumption, a sufficient number of specialized firms is required to validate the estimates. Thus, in contrast to previous translog applications, which have relied on either cost complementarity results, or approximations of scale and scope economies derived from zero replacement models, our flexible technology model demonstrates a readily estimable model, which provides theoretically consistent estimates of scale and scope economies. Thus we emphasize that contrary to accepted opinion, it is indeed feasible to accurately estimate scope economies with a translog model, provided that it is a firm type flexible model. 
For our sample of publicly owned US electric utilities, our modelling approach has not only demonstrated the feasibility, but also the necessity of relaxing the standard practice of assuming a common technology for specialized and integrated firms. While this conclusion is application specific, we nonetheless suggest that a further substantial benefit of our flexible technology model is its ability to allow readily applicable hypothesis testing of the assumption that integrated and specialized firms share a common technology. Thus, a flexible technology approach can also be applied with other functional forms such as the quadratic, and will always allow for the empirical possibility of a common technology or significant differences in technology between specialized and integrated firms. We note, however, that our proposed model does not deal with unobserved heterogeneity as our approach explicitly focuses on observable differences across firm types. Hence, we acknowledge that coefficient biases from unobserved heterogeneity may remain in our reported estimates. We therefore suggest that in future research, the firm type specific technology approach we have demonstrated here could be augmented with methods that also allow for unobserved heterogeneity.

We finally emphasize that our analysis may have significant implications for the validity of the past scope economy literature, not only in the utilities sector but also in other industries where scale and scope economies have been extensively analyzed (e.g. banking, education, transport, and the health sector). Thus, if it can be demonstrated that the production technologies employed by specialized and integrated firms differ significantly we would need to conclude that much of the past literature on scope economies might have provided biased results. It is of course impossible to draw any conclusions from our particular results about any potential general biases in the results from previous studies, given that estimates are largely affected by the definition of the input and output variables. In contrast, our contribution is therefore to emphasize that the presence of different technologies may be an important driver of economies of scale and scope (for given inputs and outputs). Such a conclusion suggests a need to reconsider the previous empirical literature, its empirical estimates, and the policy and managerial conclusions that may be drawn from it. We would argue that our approach, by allowing for both parameter heterogeneity and a straightforward means of testing for the presence of different technologies, offers an appropriate methodology to begin such an undertaking. 


\section{References}

Akridge, J.T. and Hertel, T.W. (1986). Multiproduct Cost Relationships for Retail Fertilizer Plants. American Journal of Agricultural Economics 68: 928-938.

Arocena, P., Saal, D. and Coelli, T., (2012). Vertical and horizontal scope economies in the regulated US electric power industry. Journal of Industrial Economics 60(3): 434-467.

Battese, G. (1997). A note on the estimation of Cobb-Douglas production functions when some explanatory variables have zero values. Journal of Agricultural Economics 48(2): 250-252.

Battese, G.; Malik, S.J. and Gill, M.A. (1996). An investigation of technical inefficiencies of production of wheat farmers in four districts of Pakistan. Journal of Agricultural Economics 47(2): 37-49.

Baumol, W.; Panzar, J.C. and Willig, R. (1982). Contestable Markets and the Theory of Industry Structure. Harcourt Brace Jovanovich, San Diego, California, U.S.A.

Berger, A. N., Hanweck, G. A. and Humphrey, D. B. (1987). Competitive viability in banking: Scale, scope, and product mix economies. Journal of Monetary Economics, 20(3): 501-520.

Berndt, E.R. and Khaled, M.S. (1979). Parametric Productivity Measurement and Choice Among Flexible Functional Forms. Journal of Political Economy, 87 (6): 12201245.

Bottasso, A., Conti, M., Piacenz, M. and Vannoni, D. (2011). The appropriateness of the poolability assumption for multiproduct technologies: Evidence from the English water and sewerage utilities. International Journal of Production Economics, 130(1): 112117.

Caves, D. W., Christensen, L. R. and Tretheway, M. W. (1980). Flexible cost functions for multiproduct firms. The Review of Economics and Statistics, 62(3): 477-481.

Charnes, A., Cooper, W. W. and Rhodes, E. (1978). Measuring the efficiency of decision making units. European Journal of Operational Research, 2: 429-444.

Christensen, L. R., Jorgenson, D. W. and Lau, L. J. (1973). Transcendental logarithmic production frontiers. The Review of Economics and Statistics, 55(1): 28-45.

Christensen, L.R. and Greene, H. (1976). Economies of scale in the US electric power generation. Journal of Political Economy, 84: 655-677. 
Cowing, T.G. and Holtmann, A.G. (1983). Multiproduct short-run hospital cost functions: empirical evidence and policy implications from cross-section data. Southern Economic Journal, 49, 637-653.

Färe, R. (1986). Addition and efficiency. The Quarterly Journal of Economics, 101(4): 861-865.

Fetz, A. and Filippini, M. (2010) Economies of vertical integration in the Swiss electricity sector. Energy Economics 32: 1325-1330.

Fraquelli, G., Piacenza, M. and Vannoni, D. (2005). Cost savings from generation and distribution with an application to Italian electric utilities. Journal of Regulatory Economics, 28(3): 289-308.

Fuss, M. A. and McFadden, D. (1978). Production economics: A dual approach to theory and applications. Volume I: The theory of production. North-Holland: Amsterdam.

Fuss, M. A. and Waverman, L. (1981). Regulation and the multi-product firm: The case of telecommunications in Canada, in Fromm, G. (ed.) Studies in Public Regulation MIT Press, Cambridge, MA, USA.

Fuss, M.A. and Waverman, L. (2002). Econometric cost functions, in Cave, Majumdar and Vogelsang (eds) Handbook of Telecommunications Economics Volume I: Structure, Regulation and Competition, pp. 144-177. Elsevier: Amsterdam.

Garcia, S., Moreaux, M. and Reynaud, A. (2007). Measuring economies of vertical integration in network industries: an application to the water sector. International Journal of Industrial Organization, 25: 791-820

Gilligan T. and Smirlock M. (1984). An empirical study of joint production and scale economies in commercial banking. Journal of Banking and Finance 8: 67-76

Gilsdorf, K. (1994). Vertical integration efficiencies and electric utilities: a cost complementarity perspective. Quarterly Review of Economics and Finance, 34(3):261-282.

Goisis, G., Giorgetti, M.L., Parravicini, P., Salsano, F. and Tagliabue, G. (2009). Economies of scale and scope in the European banking sector. International Review of Economics 56 (3): 227-242.

Greer, M. (2008). A test of vertical economies for non-vertically integrated firms: The case of rural electric cooperatives. Energy Economics, 30(3): 679-687.

Gunning, T. S. and Sickles, R. C. (2009). A multi-product cost function for physician private practices. Journal of Productivity Analysis, 35(2): 119-128. 
Jara-Díaz, S. and Ramos-Real, F.J. (2011). The effect of output specification on the optimal policy design for electric utilities. Journal of Regulatory Economics, 40(1): 62-81.

Jara-Díaz, S., Ramos-Real, F. J. and Martínez-Budría, E. (2004). Economies of integration in the Spanish electricity industry using a multistage cost function. Energy Economics, 26(6): 995-1013.

Jin, S.; Rozelle, S.; Alston, J. and Huang, J. (2005). Economies of scale and scope and the economic efficiency of China's agricultural research system. International Economic Review, 46(3): 1033-1057.

Kaserman, D. L. and Mayo, J. W. (1991). The measurement of vertical economies and the efficient structure of the electric utility industry. Journal of Industrial Economics, 39: 483-502.

Kim, Y.H. (1987). Economies of Scale in Multi-Product Firms: An Empirical Analysis. Economica 54 (214), 185-206.

Kuosmanen, T. (2012). Stochastic semi-nonparametric frontier estimation of electricity distribution networks: Application of the StoNED method in the Finnish regulatory model. Energy Economics 34(6): 2189-2199.

Kwoka, J. E. (2002). Vertical economies in electric power: evidence on integration and its alternatives. International Journal of Industrial Organization 20: 653-671.

Martínez-Budría, E., Jara-Díaz, S. and Ramos-Real, F. J. (2003). Adapting productivity theory to the quadratic cost function: An application to the Spanish electric sector. Journal of Productivity Analysis, 20(2): 213-229.

Mayo, J. (1984). Multiproduct monopoly, regulation and firm costs. Southern Economic Journal 51(1): 208-218.

Meyer, R. (2012). Vertical Economies and the Costs of Separating Electricity Supply - A Review of Theoretical and Empirical Literature. The Energy Journal, 33(4): 161-185.

Nerlove, M. (1963). 'Returns to Scale in Electricity Supply,' in Christ, C.F. (ed.), Measurement in Economics. Studies in Mathematical Economics and Econometrics in Memory of Yehuda Grunfeld, pp. 167-198 (Stanford University Press, Stanford, California, U.S.A.).

Panzar, J. C. and Willig, R. D. (1981). Economies of scope. The American Economic Review, 71(2): 268-272. 
Rezvanian, R. and Mehdian, S. (2002). An examination of cost structure and production performance of commercial banks in Singapore. Journal of Banking and Finance 26: 79-98.

Röller, L. (1990). Modelling cost structure: the Bell System revisited. Applied Economics, 22: 1661-1674.

Saal, D. S. and Parker, D. (2006). Assessing the performance of water operations in the English and Welsh water industry: A lesson in the implications of inappropriately assuming a common frontier. In T. Coelli and D. Lawrence (Eds.), Performance measurement and regulation of network utilities. Cheltenham: Edward Elgar.

Weninger, Q. (2003). Estimating multiproduct costs when some outputs are not produced. Empirical Economics, 28(4): 753-765.

Zellner, A. (1962). An efficient method of estimating seemingly unrelated regressions and tests for aggregation bias. Journal of the American Statistical Association, 57(298): 348-368. 
Table 1. Firm Count in Size Bracket

\begin{tabular}{lrrrrrrrrr}
\hline & \multicolumn{10}{c}{ Distribution $(\mathrm{GWh})$} \\
\cline { 2 - 10 } Generation (GWh) & 0 & $<250$ & $<500$ & $<750$ & $<1000$ & $<2500$ & $<5000$ & $<7500$ & Total \\
\hline 0 & 0 & 47 & 39 & 24 & 5 & 21 & 4 & 8 & 148 \\
$<50$ & 3 & 10 & 9 & 5 & 0 & 0 & 0 & 0 & 27 \\
$<250$ & 9 & 9 & 42 & 2 & 3 & 10 & 0 & 0 & 75 \\
$<500$ & 14 & 0 & 20 & 10 & 7 & 17 & 0 & 0 & 68 \\
$<750$ & 7 & 0 & 3 & 4 & 4 & 4 & 0 & 0 & 22 \\
$<1000$ & 13 & 0 & 0 & 0 & 0 & 5 & 0 & 0 & 18 \\
$<2500$ & 28 & 0 & 4 & 4 & 6 & 11 & 8 & 0 & 61 \\
$<5000$ & 10 & 0 & 0 & 0 & 2 & 1 & 4 & 0 & 17 \\
\hline Total & 84 & 66 & 117 & 49 & 27 & 69 & 16 & 8 & 436 \\
\hline
\end{tabular}

Table 2. Summary Statistics

\begin{tabular}{|c|c|c|c|c|c|c|c|c|}
\hline & \multicolumn{2}{|c|}{ All } & \multicolumn{2}{|c|}{ Generation } & \multicolumn{2}{|c|}{ Integrated } & \multicolumn{2}{|c|}{ Distribution } \\
\hline & mean & sd & mean & sd & mean & sd & mean & sc \\
\hline Total Cost (M.US dollars) & 28.71 & 29.92 & 39.24 & 27.07 & 36.76 & 34.11 & 11.62 & 13.44 \\
\hline $\mathrm{y}_{\mathrm{G}}$ Net Generation (GWh) & 753.46 & 847.61 & 1176.78 & 948.98 & 579.15 & 736.78 & . & . \\
\hline $\mathrm{y}_{\mathrm{D}}$ Peak Demand (MW) & 192.87 & 236.08 & . & . & 191.30 & 187.57 & 195.03 & 290.67 \\
\hline $\mathrm{y}_{\mathrm{D}}$ Retail Sales (GWh) & 855.71 & 1061.34 & . & . & 826.31 & 776.16 & 896.24 & 1361.95 \\
\hline $\mathrm{w}_{\mathrm{K}}$ Price of Capital (Rate) & 0.12 & 0.03 & 0.12 & 0.04 & 0.13 & 0.03 & 0.11 & 0.03 \\
\hline $\mathrm{wF}_{\mathrm{F}}$ Price of Fuel (M/Mbtu) & 2.25 & 1.73 & 1.28 & 0.67 & 2.65 & 1.87 & . & . \\
\hline wo $_{\mathrm{O}}$ Price of Other Inputs & 0.92 & 0.12 & 0.92 & 0.12 & 0.92 & 0.13 & 0.91 & 0.11 \\
\hline Capital share & 0.32 & 0.11 & 0.33 & 0.12 & 0.27 & 0.08 & 0.38 & 0.11 \\
\hline Fuel share & 0.31 & 0.11 & 0.36 & 0.12 & 0.29 & 0.11 & . & . \\
\hline Other input share & 0.48 & 0.16 & 0.32 & 0.13 & 0.44 & 0.10 & 0.62 & 0.11 \\
\hline Observations & 436 & & 84 & & 204 & & 148 & \\
\hline
\end{tabular}


Table 3. Parameter estimates

\begin{tabular}{|c|c|c|c|c|c|c|c|}
\hline & \multicolumn{3}{|c|}{ Model 1} & \multirow{2}{*}{$\begin{array}{l}\text { Model } 2 \\
\text { All firms }\end{array}$} & \multicolumn{3}{|c|}{ Model 3} \\
\hline & $\begin{array}{l}\text { Integrated } \\
\text { firms }\end{array}$ & $\begin{array}{l}\text { Upstream } \\
\text { firms }\end{array}$ & $\begin{array}{l}\text { Downstream } \\
\text { firms }\end{array}$ & & $\begin{array}{l}\text { Integrated } \\
\text { firms } \\
\end{array}$ & $\begin{array}{l}\text { Upstream } \\
\text { firms } \\
\end{array}$ & $\begin{array}{l}\text { Downstream } \\
\text { firms }\end{array}$ \\
\hline I & $\begin{array}{l}0.099 * * * \\
{[0.03]}\end{array}$ & & & & & & \\
\hline $\mathrm{U}$ & & $\begin{array}{l}-0.327^{* * *} \\
{[0.04]}\end{array}$ & & & & & \\
\hline $\mathrm{D}$ & & & $\begin{array}{l}-0.841^{* * *} \\
{[0.03]}\end{array}$ & & & & \\
\hline$y G$ & $\begin{array}{l}0.457^{* * *} \\
{[0.02]}\end{array}$ & $\begin{array}{l}0.866^{* * *} \\
{[0.03]}\end{array}$ & & $\begin{array}{l}0.546 * * * \\
{[0.0160]}\end{array}$ & $\begin{array}{l}0.453 * * * \\
{[0.0185]}\end{array}$ & $\begin{array}{l}0.882 * * * \\
{[0.0224]}\end{array}$ & \\
\hline $\mathrm{yD}$ & $\begin{array}{l}0.426 * * * \\
{[0.03]}\end{array}$ & & $\begin{array}{l}0.905^{* * *} \\
{[0.02]}\end{array}$ & $\begin{array}{l}0.361^{* * *} \\
{[0.0227]}\end{array}$ & $\begin{array}{l}0.446 * * * \\
{[0.0291]}\end{array}$ & & $\begin{array}{l}0.903 * * * \\
{[0.0288]}\end{array}$ \\
\hline wK & $\begin{array}{l}0.274^{* * *} \\
{[0.01]}\end{array}$ & $\begin{array}{l}0.308^{* * *} \\
{[0.01]}\end{array}$ & $\begin{array}{l}0.399 * * * \\
{[0.01]}\end{array}$ & $\begin{array}{l}0.279 * * * \\
{[0.00756]}\end{array}$ & $\begin{array}{l}0.275 * * * \\
{[0.00601]}\end{array}$ & $\begin{array}{l}0.298 * * * \\
{[0.0119]}\end{array}$ & $\begin{array}{l}0.403 * * * \\
{[0.00966]}\end{array}$ \\
\hline $\mathrm{wF}$ & $\begin{array}{l}0.293^{* * *} \\
{[0.00]}\end{array}$ & $\begin{array}{l}0.397 * * * \\
{[0.01]}\end{array}$ & & $\begin{array}{l}0.296 * * * \\
{[0.00660]}\end{array}$ & $\begin{array}{l}0.294 * * * \\
{[0.00569]}\end{array}$ & $\begin{array}{l}0.406 * * * \\
{[0.00825]}\end{array}$ & \\
\hline yG2 & $\begin{array}{l}0.105^{* * *} \\
{[0.02]}\end{array}$ & $\begin{array}{l}0.038 \\
{[0.03]}\end{array}$ & & $\begin{array}{l}0.0478^{* * *} \\
{[0.00190]}\end{array}$ & $\begin{array}{l}0.118 * * * \\
{[0.0141]}\end{array}$ & $\begin{array}{l}0.0243 \\
{[0.0173]}\end{array}$ & \\
\hline yD2 & $\begin{array}{l}0.079 \\
{[0.08]}\end{array}$ & & $\begin{array}{l}-0.252^{* * *} \\
{[0.03]}\end{array}$ & $\begin{array}{l}0.0464^{* * *} \\
{[0.00330]}\end{array}$ & $\begin{array}{l}0.0836 \\
{[0.0507]}\end{array}$ & & $\begin{array}{l}-0.230 * * * \\
{[0.0500]}\end{array}$ \\
\hline wK2 & $\begin{array}{l}0.009 \\
{[0.02]}\end{array}$ & $\begin{array}{l}-0.112 * * * \\
{[0.03]}\end{array}$ & $\begin{array}{l}0.136^{* * *} \\
{[0.03]}\end{array}$ & $\begin{array}{l}0.00529 \\
{[0.0163]}\end{array}$ & $\begin{array}{l}0.000186 \\
{[0.0183]}\end{array}$ & $\begin{array}{l}-0.0776^{*} \\
{[0.0364]}\end{array}$ & $\begin{array}{l}0.163 * * * \\
{[0.0366]}\end{array}$ \\
\hline $\mathrm{wF} 2$ & $\begin{array}{l}0.146 * * * \\
{[0.01]}\end{array}$ & $\begin{array}{l}0.206^{* * *} \\
{[0.01]}\end{array}$ & & $\begin{array}{l}0.0198 * * * \\
{[0.00472]}\end{array}$ & $\begin{array}{l}0.158^{* * *} \\
{[0.00584]}\end{array}$ & $\begin{array}{l}0.223 * * * \\
{[0.00928]}\end{array}$ & \\
\hline $\mathrm{yD}$ *yG & $\begin{array}{l}-0.110^{* * *} \\
{[0.03]}\end{array}$ & & & $\begin{array}{l}-0.0215^{* * *} \\
{[0.00123]}\end{array}$ & $\begin{array}{l}-0.118^{* * *} \\
{[0.0200]}\end{array}$ & & \\
\hline wK*yG & $\begin{array}{l}-0.023^{* *} \\
{[0.01]}\end{array}$ & $\begin{array}{l}0.011 \\
{[0.01]}\end{array}$ & & $\begin{array}{l}0.00617^{* *} \\
{[0.00238]}\end{array}$ & $\begin{array}{l}-0.0305^{* * *} \\
{[0.00623]}\end{array}$ & $\begin{array}{l}0.0150 \\
{[0.0107]}\end{array}$ & \\
\hline $\mathrm{wK} * \mathrm{yD}$ & $\begin{array}{l}0.022 \\
{[0.01]}\end{array}$ & & $\begin{array}{l}0.021 * * \\
{[0.01]}\end{array}$ & $\begin{array}{l}-0.00232 * \\
{[0.000955]}\end{array}$ & $\begin{array}{l}0.0297 * * \\
{[0.00950]}\end{array}$ & & $\begin{array}{l}0.0202 * \\
{[0.00868]}\end{array}$ \\
\hline$w F^{*} y G$ & $\begin{array}{l}0.105^{* * *} \\
{[0.00]}\end{array}$ & $\begin{array}{l}0.042^{* * *} \\
{[0.01]}\end{array}$ & & $\begin{array}{l}0.00516^{*} \\
{[0.00215]}\end{array}$ & $\begin{array}{l}0.115^{* * *} \\
{[0.00561]}\end{array}$ & $\begin{array}{l}0.0359 * * * \\
{[0.00750]}\end{array}$ & \\
\hline $\mathrm{wF}^{*} \mathrm{yD}$ & $\begin{array}{l}-0.083^{* * *} \\
{[0.01]}\end{array}$ & & & $\begin{array}{l}-0.0047 * * * \\
{[0.000827]}\end{array}$ & $\begin{array}{l}-0.0987 * * * \\
{[0.00838]}\end{array}$ & & \\
\hline $\mathrm{wF}^{*} \mathrm{wK}$ & $\begin{array}{l}-0.044 * * * \\
{[0.01]}\end{array}$ & $\begin{array}{l}-0.036^{* *} \\
{[0.01]}\end{array}$ & & $\begin{array}{l}-0.0248 * * * \\
{[0.00522]}\end{array}$ & $\begin{array}{l}-0.0571^{* * *} \\
{[0.00746]}\end{array}$ & $\begin{array}{l}-0.0609 * * * \\
{[0.0127]}\end{array}$ & \\
\hline Constant & & & & $\begin{array}{l}0.109 * * * \\
{[0.0226]}\end{array}$ & $\begin{array}{l}0.0899 * * * \\
{[0.0234]}\end{array}$ & $\begin{array}{l}-0.332 * * * \\
{[0.0262]}\end{array}$ & $\begin{array}{l}-0.855^{* * *} \\
{[0.0412]}\end{array}$ \\
\hline Observations & 436 & & & 436 & 204 & 84 & 148 \\
\hline RSS & 32.90 & & & 37.82 & 12.46 & 4.26 & 16.13 \\
\hline RMSE & 0.27 & & & 0.29 & 0.25 & 0.23 & 0.33 \\
\hline $\mathrm{Ll}$ & 1104.55 & & & 812.22 & 612.22 & 241.09 & 82.86 \\
\hline R-squared & 0.95 & & & 0.92 & 0.92 & 0.93 & 0.87 \\
\hline
\end{tabular}

Notes:

yD is Peak Demand (MW).

Standard errors in brackets.

${ }^{*} \mathrm{p}<0.05,{ }^{* *} \mathrm{p}<0.01,{ }^{* * *} \mathrm{p}<0.001$ 
Table 4. Inference on Common Technology

\begin{tabular}{llll}
\hline & All & Upstream & Downstream \\
\hline$N$ & 436 & 436 & 436 \\
Chi2 & 872.69 & 393.52 & 2575.09 \\
DF & 16 & 15 & 16 \\
$\mathrm{p}$ & 0.00 & 0.00 & 0.00 \\
\hline
\end{tabular}

Null hypothesis is that single technology is nested in separate technologies

Table 5. Economies of scale and scope at the sample mean

\begin{tabular}{lcc}
\hline & $\begin{array}{c}\mathrm{y}_{\mathrm{D}}=\text { Peak } \\
\text { demand }\end{array}$ & $\begin{array}{c}\mathrm{y}_{\mathrm{D}}=\text { Power } \\
\text { distributed }\end{array}$ \\
\hline $\begin{array}{l}\text { Model 1: Firm type flexible technology } \\
\text { S (I) }\end{array}$ & 1.132 & \\
S (U) & 1.155 & 1.148 \\
S (D) & 1.105 & 1.113 \\
SC & 0.043 & 0.009 \\
\hline Model 2: Common Technology & & \\
(zero values replaced by 0.0001) & & \\
\hline S (I) & 1.102 & 1.052 \\
S (U) & 0.701 & 0.866 \\
S (D) & 1.293 & 1.158 \\
SC & 0.401 & 0.352 \\
\hline Model 3: Separate regressions & & 1.091 \\
\hline S (I) & 1.112 & 1.130 \\
S (U) & 1.134 & 1.116 \\
S (D) & 1.108 & 0.006 \\
SC & 0.044 & \\
\hline
\end{tabular}

